\title{
NUMERICAL MODELING OF THE EFFECT OF THAWING OF SOIL IN THE AREA OF PLACING TANKS FOR STORAGE FUEL OF THERMAL POWER PLANTS AND BOILER
}

\author{
$V . Y u$. Polovnikov ${ }^{1, *}, V . Y u$. Ozhikenova $^{1}$, and F.T. Makhsutbek ${ }^{1}$ \\ ${ }^{1}$ National Research Tomsk Polytechnic University, 634050 Tomsk, Russia
}

\begin{abstract}
This paper describes the numerical modeling of heat transfer in the area placing of the tank for storage fuel of thermal power plant and boiler with considering the influence of thawing of the soil. We have established that the thawing of the soil in the area of placing of the tank for storage fuel of thermal power plant and boiler have little effect on the change of heat loss.
\end{abstract}

\section{INTRODUCTION}

Oil is used by more than 200 thermal power plants (TPP) in Russia as a primary or backup fuel. The main problem of its use - is ensuring uninterrupted supply of boilers by heated and filtered oil in the winter. Thus on heating oil during its preparation for burned (in order to reduce viscosity is exponentially dependent on the temperature) is expended considerable part of the generated electricity of TPP. Reducing these costs is one of the important tasks. Its solution is possible at optimal thermal conditions in fuel oil storage and systems supply that fuel [1].

The research of thermal modes of different objects (a residential building, a hot water pipes, a fuel storage tank et al.) is an important problem [2].

Currently, the method of calculation and design of a fuel storage tank does not take full account of all processes in a tank, that occur during the preparation of a fuel oil for combustion.

One of the most promising approaches to research of different equipment is the use of a computer programs. They take into account various effects and processes in the system of heat transfer.

The objective is the mathematical modeling of the thermal loss of fuel storage tank and numerical analysis of thermal conditions of the tank.

\footnotetext{
Corresponding author: polovnikov@tpu.ru
} 


\section{Problem statement}

We consider a typical vertical cylindrical steel underground tank. figure 1 shows a schematic representation of the field solution of the problem. For the domain under consideration (fig. 1) we solve a 2D linear and stationary problem of heat transfer in conditions of thawing of the soil .
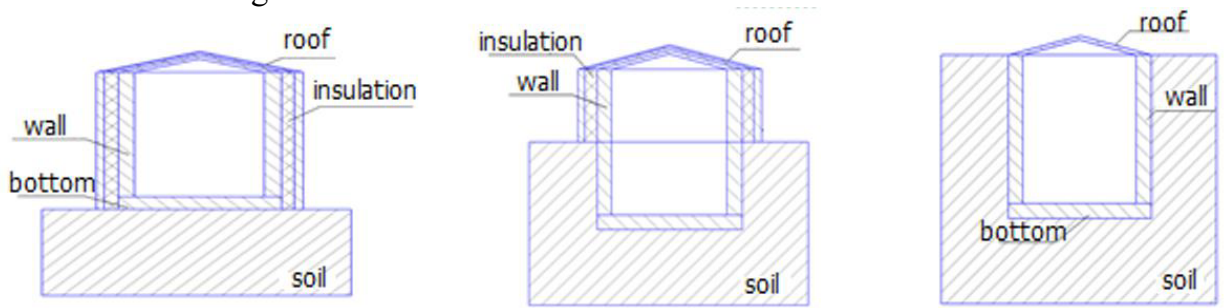

Fig. 1. Schematic representation of the field solution of the problem.

Formulating the problem, we used the following assumptions:

1. The heat transfer processes in the internal and the external environment are disregarded.

2. Thermophysical characteristics of materials used in the analysis are constant and known values.

3. There is an ideal thermal contact conditions at the boundaries.

4. The heat in the decision domain (fig. 1) is transferred only by conduction;

5. The interface between white and frozen ground has a constant temperature of $273 \mathrm{~K}$.

The listed assumptions, on the one hand, do not impose constrains of principle on the physical model of the system (fig. 1), but, on the other hand, allow one to simplify in a certain manner the algorithm and method for solving the posed problem.

\section{Mathematical model}

The processes of heat transfer to the object under consideration (fig. 1) will be described by the following equation:

$$
\begin{gathered}
\nabla^{2} T_{\mathrm{ins}}=0 ; \\
\nabla^{2} T_{\mathrm{tg}}=0 \\
\nabla^{2} T_{\mathrm{fg}}=0 . \\
T_{\mathrm{ins}, 1}=T_{\mathrm{oil}}=\mathrm{const} . \\
\lambda_{\text {ins }} \operatorname{grad}\left(T_{\mathrm{ins}, 2}\right)={ }_{\lambda t \mathrm{~g}} \operatorname{grad}\left(T_{\mathrm{tg}, 2}\right) ; T_{\mathrm{ins}, 2}=T_{\mathrm{tg}, 2} \\
\lambda_{\mathrm{fg}} \operatorname{grad}\left(T_{\mathrm{fg}, 3}\right)=\lambda_{\mathrm{tf}} \operatorname{grad}\left(T_{t \mathrm{~g}, 3}\right) ; T_{\mathrm{tg}, 3}=T_{\mathrm{fg}, 3} . \\
-\lambda_{\mathrm{g}} \operatorname{grad}\left(T_{\mathrm{g}, 4}\right)=\alpha\left(T_{\mathrm{g}, 4}-T_{\mathrm{ex}}\right) ; \\
\operatorname{grad}\left(T_{\mathrm{g}}\right)=0, x_{\rightarrow \pm \infty}, y_{\rightarrow-\infty} ;
\end{gathered}
$$




\section{Method of solution and Initial data}

The system of equations (1)-(12) was solved by the software package COMSOL Multiphysics using the module General Heat Transfer.

In carrying out a numerical simulation assumed that the surface temperature of the inner tank $\mathrm{Tm}=60^{\circ} \mathrm{C}$. Ambient temperature tex $=-40^{\circ} \mathrm{C}$.

Table 1 shows the thermal characteristics of materials and substances used in research $[2,3]$.

Table 1. Thermal properties of materials.

\begin{tabular}{|c|c|c|c|c|c|c|}
\hline \multirow{2}{*}{ Material } & \multirow{2}{*}{ Foundation } & \multirow{2}{*}{$\begin{array}{c}\text { Thermal } \\
\text { insulation }\end{array}$} & & \multicolumn{4}{|c|}{ Clayey } & \multicolumn{2}{|c|}{ Sandy } \\
\cline { 4 - 7 } & & & Frozen & Thawed & Frozen & Thawed \\
\cline { 4 - 7 } & & & & & & \\
\hline$\lambda,[\mathrm{W} /(\mathrm{m} \cdot \mathrm{K})]$ & 1.54 & 0.046 & 1.1 & 1.3 & 2.3 & 3.7 \\
\hline$c,[\mathrm{~J} /(\mathrm{kg} \cdot \mathrm{K})]$ & 887 & 840 & 1231 & 959 & 1486 & 1005 \\
\hline$\rho,\left[\mathrm{kg} / \mathrm{m}^{3}\right]$ & 2200 & 150 & 1700 & 1700 & 2000 & 2000 \\
\hline
\end{tabular}

\section{Results of numerical simulation}

The main results of numerical modeling of thermal conditions of the system under consideration (fig. 1) are listed in Table 2 and in fig. 2.

Table 2 lists the results of numerical experiments of the heat loss of a vertical cylindrical steel tank (Q1 is the heat loss excluding thawing of soil and Q2 is the heat loss, taking into account the soil thawing).

Table 2. Results of the calculation of heat loss.

\begin{tabular}{|c|c|c|c|c|c|c|c|}
\hline \multirow[t]{2}{*}{ Tank } & \multirow{2}{*}{$\begin{array}{c}\alpha, \\
{\left[\mathrm{W} /\left(\mathrm{m}^{2} \cdot \mathrm{K}\right)\right]}\end{array}$} & \multicolumn{3}{|c|}{ Clayey soil } & \multicolumn{3}{|c|}{ Sandy soil } \\
\hline & & $\mathrm{Q}_{1},[\mathrm{~W}]$ & $\mathrm{Q}_{2},[\mathrm{~W}]$ & $\delta, \%$ & $\mathrm{Q}_{1},[\mathrm{~W}]$ & $\mathrm{Q}_{2},[\mathrm{~W}]$ & $\delta, \%$ \\
\hline \multirow[t]{4}{*}{ Underground } & 5 & 1674.78 & 1653.66 & 1.26 & 2032.78 & 1986.31 & 2.30 \\
\hline & 10 & 1964.89 & 1944.54 & 1.03 & 2341.20 & 2298.87 & 1.81 \\
\hline & 15 & 2097.16 & 2075.04 & 1.06 & 2481.31 & 2438.14 & 1.74 \\
\hline & 25 & 2219.69 & 2198.03 & 0.98 & 2610.27 & 2568.69 & 1.59 \\
\hline \multirow{4}{*}{$\begin{array}{c}\text { Semi- } \\
\text { underground }\end{array}$} & 5 & 1978.62 & 1962.83 & 0.8 & 2261.58 & 2237.19 & 1.08 \\
\hline & 10 & 2298.00 & 2282.66 & 0.23 & 2596.17 & 2573.79 & 0.86 \\
\hline & 15 & 2440.07 & 2424.01 & 1.15 & 2743.09 & 2721.59 & 0.78 \\
\hline & 25 & 2574.73 & 2556.47 & 0.59 & 2879.79 & 2856.26 & 0.82 \\
\hline \multirow[t]{4}{*}{ Aboveground } & 5 & 2461.77 & 2455.46 & 0.26 & 2574.17 & 2571.52 & 0.1 \\
\hline & 10 & 2832.79 & 2826.54 & 0.22 & 2948.62 & 2941.88 & 0.23 \\
\hline & 15 & 2993.21 & 2987.41 & 0.19 & 3110.68 & 3110.40 & 0.01 \\
\hline & 25 & 3140.79 & 3135.03 & 0.18 & 3259.91 & 3258.75 & 0.04 \\
\hline
\end{tabular}

Numerical analysis results indicate that the presence of thawing of soil in the container placement area for the storage of fuel thermal power plants and boiler houses does not lead to significant changes in the thermal regime of the object.

Figures 2 show the typical temperature fields in the area of storage tanks for fuel thermal power plants and boiler plants, taking into account the freezing of sandy and clay soil. 

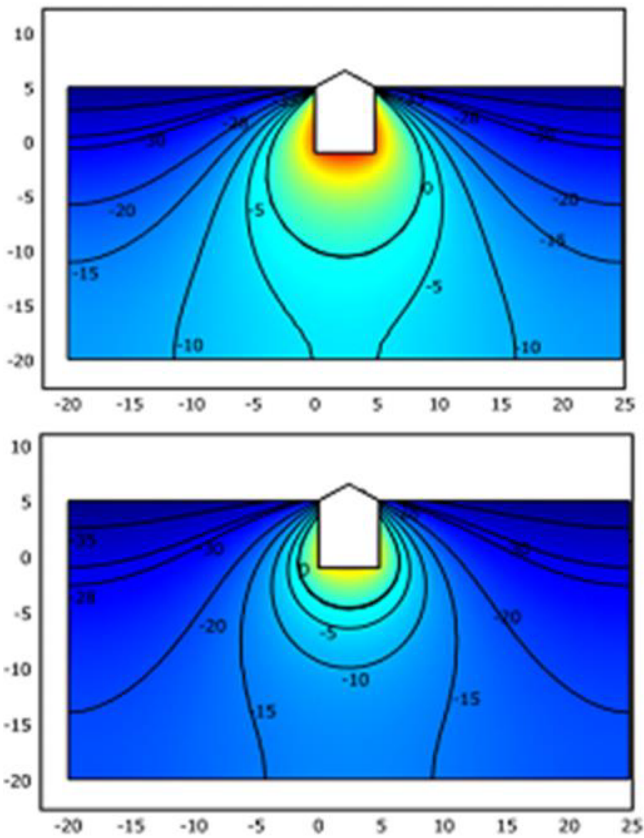

Fig. 2. Typical temperature field in the zone of the storage tanks for fuel thermal power plants and boiler.

\section{Conclusion}

The numerical analysis of thermal conditions and heat losses of tanks (tab.2 and fig.2) for storing fuel thermal power plants and boiler in the conditions of freezing and thawing of the soil, the area defined frozen and thawed areas. The relative change of the heat losses of tanks simulation results in terms of soil freezing in their distribution area is $0.98-2.30 \%$ for underground and $0.04-0.26 \%$ for the land, $0.23-1.15 \%$ for the semi-underground reservoirs. In addressing this problem it found that the inclusion of soil thawing in the area of the tank placement for storing fuel thermal power plants and boiler houses does not lead to significant changes in the thermal regime of the object.

\section{Notations}

$T$ - temperature, $\mathrm{K} ; \lambda$ - coefficient of thermal conductivity, $\mathrm{W} /(\mathrm{m} \cdot \mathrm{K}) ; \alpha-$ the heat transfer coefficient, $\mathrm{W} /\left(\mathrm{M}^{2} \cdot \mathrm{K}\right)$.

Indexes: ins - a layer of heat insulation; $\mathrm{g}$ - ground; tg - thawed ground; fg - frozen ground; oil - oil; ex - external; 1 - the inner surface of the tank insulation; 2 - the boundary between "shell of tank - ground"; 3 - the boundary between "thawed ground - frozen ground"; 4 - the boundary between "soil - environment".

\section{References}

1. S.A. Kuznetsova EPJ Web Conf. 82 (2015)

2. V.Yu. Polovnikov, E.V. Gubina, J. Eng. Phys. Thermophys. 87 (2014)

3. V.Yu. Polovnikov, E.S. Glazyrin, EPJ Web Conf. 82 (2015) 